\title{
Análise poética integral de "Negra sombra"
}

\author{
Xosé Azar
}

pepegcasal@gmail.com

\section{LIMIAR}

Partimos da concepción da poesía (e de todas as artes) como da integración dun fondo cunha forma, pero, ademais, sabemos que hai uns poemas e unha arte en xeral que non fican só no sentimento e a beleza, senón que teñen a arela de algo que está antes e é a súa orixe: o trasfondo. Como o poema co que imos traballar pertence a esta segunda clase (poesía esencial ou vital) que, ademais do fondo oculta un trasfondo, cómpre comezarmos por isto último. A miña hipótese é que se trata do desentrañamento, que é un concepto filosófico desenvolvido no cap. 14 de Vida masculino/ femenina (Azar 2004). En Poética de Fondo (Azar 2007) considérase a raigaña da poesía máis fonda, e partindo del analízase a obra de nove poetas: Hölderlin, Byron, Baudelaire, Poe, Nerval, Rosalía, Rilke, Machado e Juan de la Cruz. Trátase dun sentimiento actual que naceu dunha integración primixenia deficiente, ao mesmo tempo ferida e manancial, sufrimento e capacidade creadora. Para expresalo no seu poema, Rosalía válese dunha instancia animista, a negra sombra, e o fondo do poema consiste na invasión da escritora por una fada marabillosa, primeiro trascendente pero que finalmente se recoñece inmanente, pasando o poema así a facerse filosófico.

A forma ten que axudar a analizar este asoballamento imaxinario, porque precisamente é ela quen o vai facendo. Na miña Poética formal (Azar 2013) hai unhas formas básicas que son as sínteses progresivas que fan o movemento que é un poema. Con elas intentarei formalizar este; hai tamén outras formas máis amplas que expresan a súa natureza xeral. E con todas elas organizarei a súa secuencia formal. Finalmente na definición farei a integración de trasfondo, fondo e forma.

\section{POÉTICA DE FONDO}

Antes de nada, imos investigar un pouco este desentrañamento rosaliano. Xa na primeira obra aparece: é natural, pois trátase dun libro escrito tras a averiguación, de maneira traumática, de quen era seu pai. É máis sorprendente que apareza tamén en Cantares gallegos, que é unha obra de exaltación da Terra; porén, vémolo alí puxante:

Mais o que ben quixo un día si a querer ten afición, sempre lle queda unha mágoa dentro do seu corazón (De Castro 1995: 234)

aló gardo non sei donde saudades de non sei cando (1995: 213)

E temos tamén a testemuña do marido: "Aquellas estrofas, breves y cadenciosas... Están llenas de la esencia de sus dolores" (Murguía 1975: 194). Pero, como se sabe, é en Follas Novas e En las orillas del Sar onde se amosa enteiramente, nas súas dúas ramas de anhelo e desarraigamento; o primeiro é unha ansia que non ten fin, e o segundo, un desasosego maior, sempre mesturados os dous nela, en maior ou menor medida. Das imaxes para figuralo a máis frecuente é a sede, que é máis ben anhelo: 
Anque me des viño do Riveiro de Avia [...] ña madre querida, non se que me falta (De Castro 1993a: 362)

Da sede que me abrasa, craras fontes, apagade o queimor

(1993a: 151)

\section{O deserto páramo é claramente desarraigamento:}

Cando un é moi dichoso, moi dichoso, ¡incomprensibre arcano! casi (n'é mentira anque o pareza)

lle a un pesa o ser tanto.

¿Que no fondo ben fondo das entrañas hai un deserto páramo que non se enche con risas nin contentos, senón con froitos do delor amargos!

(1993a: 127)

Do contacto de Rosalía con Poe, como de todo o que atinxe a algún aspecto da intimidade de Rosalía, temos moi poucas noticias, porque o marido era moi reservado con respecto a ela. Nunha das poucas cartas dela que el non destruíu, que pertence á época primeira de La hija del mar e A mi madre, hai unha referencia ao poeta norteamericano: "He leído ayer un cuento de Poe, precioso aunque sencillo. Allí comprenderás que era poeta" (De Castro 1993b: 602, 2). Considérao poeta aínda que está falando de relatos, o que implica que coñecía del, polo menos, $O$ corvo, publicado trece anos antes e de gran éxito tanto en América como en Europa. Unha mostra deste coñecemento temperán tal vez sexa esta pasaxe de La hija del mar:

— ¡Matad aquel pájaro! Matadle pronto porque me duele el corazón cuando le veo [...] lo he sentido ya entrar en mi corazón... él me martiriza... él me mata [...]

- [...] yo seré tu médico, yo te sacaré del pecho ese pájaro maldito, yo te salvaré... ¿No es verdad que yo sólo soy el que puede salvarte?

- Sí, sí - le respondía la pobre loca mirándolo con espantados ojos; tú, eres bueno, busca ese pajaro dentro de mi pecho y mátale... (1993b: 167-168, 1)

A agonista fala dun paxaro negro pero, como se ve a continuación ("la golondrina mojaba en la corriente las puntas de sus negras alas..."; 1993b: 182); trátase dunha andoriña, que nomeamos polo xénero gramatical feminino. O esperado sería: 'la he sentido...'; é probable que lle chame 'paxaro' por influencia de $O$ corvo:

Vuelve a la tempestad [...]

¿Sea esa palabra nuestra señal de despedida, [pájaro o enemigo [...]

¿No dejes ninguna pluma negra [...]

¿Saca tu pico de mi corazón [...]!

(Poe 2000: 213)

Tamén no final da súa vida temos probas desta influencia, na súa derradeira novela, El primer loco, que podería considerarse unha lenda de Bécquer tratada ao modo dos relatos de Poe, pois a parte lírica máis superficial é de influencia do primeiro e a máis dramática e obsesiva do segundo -se ben a paixón inmensa que triunfa nela supere con moito aos dous. Xa externamente vese esta pegada no nome da protagonista (Berenice), que coincide co dun relato poeano, no que a obsesión son os dentes da amada que, cando parece que está morta, o agonista arrinca. Aquí hai algo semellante:

inmóvil, y con los ojos clavados en los míos empezó a mirarme [...] y al mismo tiempo que me miraba así sonreíase enseñando los dientes [...] astillas puntiagudas, que me parecían herir sus labios sonrosados. (De Castro 1993b: 744, 2)

Polo tanto, a influencia de Poe sobre a nosa poeta esténdese durante toda a súa vida; ambos os dous son irmáns porque os dous son fillos de Byron, aínda que máis atormentados que seu pai, máis introvertidos, máis fondos poetas. Porén, os camiños dos dous diverxen, pois Poe realízase máis ben no relato, porque a súa mente analítica necesita, como Kafka, expresarse na extensión e no detalle; en cambio, Rosalía é unha novelista fracasada, o seu medio de expresión é o poema curto, fondo, sinxelo; odia a exhibición e o narcisismo -e, dentro da súa tortura, plácido. Poe é o irmán maior de Rosalía e Byron é o pai; sen a súa rebeldía morrería no ambiente conservador compostelán ao que a fixo regresar o marido, e Poe axudouna a buscarse. Participaban os dous dun desentrañamento semellante, e sobre todo a influencia nela vén de $O$ corvo. Esta obra está na xénese de A mi madre, así como o Manfredo de Byron está na de La hija del mar. Tanto en Poe 
como en Castro trátase dunha morta - a amada (inventada) nun caso; a morte real da nai no outro- cuxo espectro se teme, e así como no poema poeano a noiva vai sendo substituída polo desentrañamento do propio agonista, en Rosalía A mi madre acada unha virulencia imparable, que só poderá ser reelaborada e admitida como algo propio en "Negra sombra". En A mi madre, como en $O$ corvo, o estrañamento é máximo: a primeira parte do poema rosaliano ten que ser un pranto; aí pouca orixinalidade cabía, pero na segunda, enteiramente persoal sen nada que ver coa tradición, Rosalía, condicionada pola vivencia traumática da morte, saca do máis fondo de si o reproche que había nela soterrado, pois xamais puido asumir que súa nai cando naceu a abandonase. En Poe o ser querido convértese ao comezo nun corvo, pero deseguido o corvo pasa a ser o propio poeta. Rosalía ten que reconverter o seu desentrañamento para facelo creador, e este traballo é a negra sombra. Nos dous casos algo sombrío advén de carácter animista. Tamén en Rosalía se supón que é de noite, preto do soño, "ó pe dos meus cabezales". A sombra búrlase; tamén o corvo ao comezo vai desenvolvendo un aspecto risible, na quinta volta: "pero el cuervo seguía cautivando mi imaginación y haciéndome sonreír [...] ese lúgubre, desgarbado, fantasmal..." (Poe 2000: 211); en Rosalía: "tornas facéndome mofa" (De Castro 1993a: 170). En ambos os dous casos trátase dunha especie de obsesión diabólica, aparentemente sinistra pero no fondo esperanzada, sobre todo en Rosalía. No final de Poe, o agonista aferrado na sombra do corvo soña cunha deusa:

$$
\begin{aligned}
& \text { Y el cuervo nunca se marchó, aún está } \\
& \text { [parado, está parado } \\
& \text { en el pálido busto de Palas [...] } \\
& \text { y sus ojos se asemejan a los ojos de un } \\
& \text { [demonio soñara }
\end{aligned}
$$

(Poe 2000: 213)

O remate de Rosalía é unha servidume, pero tamén unha posibilidade:

en todo estás e ti es todo pra min (De Castro 1993a: 171)

E co 'nunca máis' de Poe correspóndese en Rosalía o 'sempre': y mi alma de esa sombra que se extiende [sobre el suelo

¡no se alzará nunca más!

(Poe 2000: 215)

¡sombra que sempre me asombras!

(De Castro 1993a: 171)

O agonista aferrado na sombra do corvo soña nunha deusa; Rosalía no comezo quería que a sombra fuxise, pero ela se converte no entorno e apodérase da poeta, e convértese nela mesma e xa non se irá nunca dela, nunha posesión ambivalente entre opresiva e creadora. Polo tanto, en Rosalía pásase da sombra á propia creación atormentada; en Poe: da noite a una imposible alba.

A comparación tamén da negra sombra coa noite escura de Juan de la Cruz axudaranos a comprender mellor as dúas bilateralidades, xa que ambas as dúas son a máis fonda expresión do desentrañamento. Que Rosalía sufriu tamén a influencia de Juan de la Cruz, aínda que non o saibamos documentalmente, vémolo sobre todo nos seus poemas de amor absoluto, que son tan místicos coma eróticos. A semellanza chega ás veces aos mesmos termos. Así en Rosalía:

En medio del silencio, allá en la noche, madre de los misterios,

llenaban el espacio ecos suavísimos, armónico concierto

de entrecortadas frases y caricias de suspires de quejas y de besos.

¡Ay! Eran él y ella, espiritus de fuego almas que envueltas en ardiente llama devoraban placeres y deseos [...] (1993b: 575, 2).

E así en Juan de la Cruz:

Esta llama de amor es el Espíritu de su Esposo..., al cual siente el alma en sí, no sólo como fuego que la tiene consumida y transformada en sí, sino como fuego que además de eso, arde en ella y echa llama. (De la Cruz 1993: 788)

A negra sombra e a noite escura parécense demasiado para non ter que preguntarmos se Juan de la Cruz non parte tamén do desentrañamento materno para chegar ao entrañamento 
poético e espiritual. As dúas considéranse inimigas e os dous poetas teñen que loitar con elas para arrincarlles a vida que teñen. Juan de la Cruz sabe que na noite está a alba e Rosalía sabe que a negra sombra a fixo creadora; probablemente o primeiro non relacione a súa invención co propio desentrañamento, pero sabemos que cando naceu acababa de morrer o pai e que a nai era tecedeira e que había moita pobreza na casa, polo que non tivo que ser moi ben acollido; de Rosalía, en cambio, sabemos, pola súa novela La hija del mar, que era consciente de que era a súa infancia conflitiva a que a facía creadora. Aínda que os dous andan por diferentes camiños, van ao mesmo sitio: á paridade entrañamento/estrañamento. A negra sombra chega en contra dos desexos da agonista e convérteo todo a si mesma: atrévese co mesmo sol, que xa que a poeta vive no estrañamento, será agora un pouco máis alleo; a estrela convertirase en anhelo, o vento chorará; nos cantos haberá ansia e nos choros desesperación; o río terá saudade da fonte e aspirará á mar; pero a noite e a aurora son de Juan de la Cruz, de tal modo que a maior escuridade é para el a alborada; ambas as dúas creacións son a vía desentrañal pola que encamiñan, el a súa relixión, e ela a existencia e a creación poética. O símbolo de Rosalía é máis xeral, tende máis á filosofía, mentres que o de Juan de la Cruz, en resumidas contas, quere ser só un camiño para o espírito. Cando a pelexa cesa e a sombra a fai súa, Rosalía ve que medrou para ela, que xa nunca a abandonará: unha poetisa presa da súa sombra que a enlouquece e a converte de ensombrecida a asombrada. Entón é cando pode dicirlle: "en todo estás e ti es todo/ pra min e en min misma moras" (De Castro 1993a: 171), que é o recoñecemento de que se trata da súa propia alma. A sombra é unha borracheira ou unha enfermidade que a trastorna e a transforma existencialmente. $\mathrm{Na}$ última estrofa Rosalía comproba todo o perdido e gañado nesta invasión; sabe que é xa dela para sempre e tamén ao revés: "en todo estás e ti es todo/ pra min" (1993a: 171). Con isto quere dicir que foi unha ganancia e non unha perda, e sabe que nunca estará sen ela, polo que, aínda que sexa sufrimento, é tamén enriquecemento, como en Juan de la Cruz. Así, o poema que comezou no estrañamento acaba no entrañamento. Polo tanto, os procesos son semellantes, el sabe que a noite é escura, pero que é tamén espiritual e unha cousa esixe a outra; Rosalía sabe que o desentrañamento lle fai sufrir, pero que tamén a fai creadora. Estar na noite é tamén estar no espírito; estar na sombra é tamén estar na poesía: paridade noite escura / espíritu, e negra sombra / arte. Non se podería dicir só noite ou sombra, pois cando a noite se fai escura é cando se fai mística, e cando a sombra se fai negra é cando se fai creadora.

Desta maneira québrase a codia do sentido común mundano e entón podemos achegarnos ao manancial desentrañal, orixe da arte e do espírito. A grandeza dun poema mídese pola súa capacidade de rachar a realidade aparente, porque é mentireira, e expresarse desde o máis belo ou monstruoso que haxa no máis fondo. Os dous poetas buscan a vivencia primordial; os dous son uns desentrañados que non poden vivir sen algo que lles falta, que el atopa polo camiño da religación espiritual e ela polo soño erótico e a creación existencial. Os dous poemas pasan do alleamento á totalidade. $\mathrm{Ne}$ gra sombra é unha invasión: hai unha primeira onda, é a primeira estrofa, contida polo desexo da agonista de que non a sobrepase; unha segunda na que a onda rompeu xa o dique; unha terceira en que xa non hai máis que a vida que a sombra trae; e unha derradeira que é sabedoría, totalidade e confianza cara ao futuro. Se a comparamos con Noche oscura, nos dous casos hai unha única actividade que supera ao agonista, que quere interferir, mais en ambos os dous casos pouco a pouco vaise dando conta da grandeza da invasión. A negra sombra é máis aparente e a noite escura máis soterrada, e complementariamente a actividade en Rosalía é máis un feminino recibir e en Juan de la Cruz unha desesperación de pensar que non acada o espírito. Non vale para nada querer ou non querer, pois tanto na sombra como na noite sucede como se di nos Evanxeos: "O vento sopra onde quere e ti séntelo zoar pero non sabes de onde vén nin para onde vai" (S. Xoán $3,8)$. Estes dous símbolos desentrañais son tan parecidos que se poderían intercambiar, facendo espiritual a negra sombra e existencial a noite escura. Verdadeiramente, o artista 
que intenta facer a súa obra está na mesma situación que Juan de la Cruz, nunha agonía semellante. E da sombra negra rosaliana, se a convertésemos na nosa deusa, espiritualmente poderiamos -como no poema- seguir dicindo que é todo e que eu son dela, aínda que ela sexa a miña obra. A negra sombra é menos dramática, máis pracenteira, menos desesperada; se a fixeramos mística, teriamos unha relixión máis feminina, galaica, e se fixeramos a noite escura creadora, gañaría en fondo a obra, pois arrancariamos dun fondo más impotente. Podería pregárselle véndoa como unha instancia miña pero superior á miña vontade; sería facer filosófica a relixión, pois a negra sombra en si mesma non é nada, só a propia actividade, a propia disposición creadora. Faríase así mística a Rosalía, que tan preto está do espírito no seu eros deica a morte dos poemas XXIII, XXIV, XXIX, XLIX da nosa escolma (Azar 2009); o eros de Rosalía neses poemas é místico e inmanente. Juan de la Cruz tamén gañaría, desdogmatizaríase, desubstanciaríase, desautorizaríase, deitaría fóra a patadas o inferno, o temor. Se a negra sombra fose a doctrina de Juan de la Cruz, a relixión trascendente converteríase en filosófica. Con Rosalía mística teriamos unha relixión materna e galaica, en lugar da castelá proclive ao duro ascetismo; a relixión inmanente do máis filosófico dos místicos cristiáns afondaría a nosa brandura.

\section{POÉTICA FORMAL}

Para a comprobación do fondo e o trasfondo valémonos da Poética formal (Azar 2013), que é unha teoría elaborada por min partindo da experiencia na creación poética, propia e allea.

É necesario saber que a forma, en todas as artes, é relación. Se compoño una escultura intento relacionar esta curva con esoutra, ou esta cor verde con aquela amarela se estou pintando; e se fago poesía vou compoñendo a peza relacionando primeiro en sentido horizontal -síntese- en cada verso, e despois en sentido vertical -adición- para facer as estrofas e o poema enteiro. Polo tanto, hai, en principio, dúas formas básicas que son a síntese e a adición: tres posibilidades de síntese e tres de adición, como se mostra a continuación. A seguir recóllense todas as formas rexistradas de acordo coa terminoloxía empregada na miña Poética formal (Azar 2013: 36). Categorías formais da poesía:

Formas básicas:

- Síntese ou aestancia:

- contrastancia ou contrasentido (oposición tese/antítese) /+/

- conestancia ou consentido (concordancia tese/epítese) / =/

- desestancia ou disentido (discordancia tese/parátese) /x/

- Adición ou enestancia:

- soestancia (sucesión crecente ou decrecente) $/></$

- restancia (reiteración semellante) /V/

- sinestancia (ao chou) $/ \wedge /$

Formas imaxinarias:

- inestancia (suxerir) /I/

- antestancia (metáfora e semellantes /S/

- entrestancia (outredade) /2/

- trasestancia (visión, transformación) /T/

As formas imaxinarias comprenden todo o poema, son como a súa culminación; as básicas son os ladrillos e as imaxinarias o edificio. Pero con respecto á sintese, é conveniente que saibamos que hai, ademais, unhas máis complexas, porque xuntan, nunha soa expresión, varios sentimentos, opostos ou diversos e, polo tanto, son máis interesantes e poéticas; nelas a nosa poeta está moi avezada. Xeralmente trátase dunha complexión de contrasentido e consentido, na que pode dominar a unha ou a outra síntese; tamén de contrasentido e disentido. Estas catro son as mesturas que eu atopei:

- Mixtión contraconestante ou positiva: xuntos amándonos / 1 / morramos (Azar 2010: 49) mais a do triste $/ \pm /$ sorrir (2010: 27)

- Mixtión concontrastante ou negativa: ignorando que hai labios / $\neq$ / que secan $/>/$ y que manchan cuanto tocan (2010: 73) 
- Mixtión descontrastante (escarnio):

I eu desde o meu corruncho /*/ sorreireime / $>$ | cun sorrir $/ \pm * /$ triste e negro

(2010: 43)

En todas elas, como se ve, a contrastancia é fundamental; pero hai outra clase míxtica na que non hai nin contra nin disentido, que non se refire só a dous termos senón ao sentido xeral que expresa un sentimento de inmersión: a totalización

En los ecos del órgano o en el rumor del [viento,

en el fulgor de un astro o en la gota de lluvia

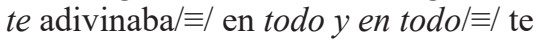

sin encontrarte nunca

[buscaba $/+1$

(2010: 129)

Seguramente Rosalía de Castro aprendeu de Juan de la Cruz. A continuación, vemos nel unha mixtión positiva e outra total:

Ya toda cauterizada y hecha una llaga $/ \pm /$ de [amor, está toda sana $/=/$ en amor,

porque está transformada/三/ en amor

(De la Cruz 1993: 809)

Rosalía foi unha boa discípula, que matizou e ampliou a ensinanza recibida, reducida no seu mestre ao campo espiritual, que ela estendeu tamén ao erótico e ao existencial. A nosa poeta séntese ás veces estraña ao mesmo tempo que entregada, dous sentimentos opostos xuntos, e iso acrecenta a beleza, como na música. A agonista no que segue, expulsada da mar materna, queda non sendo de ninguén e, polo tanto, de todo; os dous sentimentos mesturados, o de soidade e o de totalidade, a tristeza e a liberación:

[...] botouna fóra o mar $/+/$

i alí onde o corvo pousa $/ \neq / \mid \equiv /$

soia enterrada está

(De Castro 1993a: 195)

Estoutro é un exemplo de eros total, no que a morte acrecenta a vida, como en Juan de la Cruz:

Sueño en el silencio

de la noche callada

que a mi lecho se acerca

como una sombra voptuosa y blanca $[. .$.
Ven, báñáte en las ondas / $\neq / / \equiv /$ de la muerte mi cariñosa hermana [...]

(De Castro 1993b: 571, 2)

Antes de comezar o estudo formal de "Negra sombra", é necesario saber que un verdadeiro poema, un poema vital, que é o único que nos interesa aquí, é un movemento que pode ir medrando en intensidade (propiciación), ou comezar desde a altura máxima (tránsito) e logo decaer (sosego) ou acabar de repente. Para que sexa un proceso e non unha aseveración queda, debe ter cando menos dous deses tres momentos. Así mesmo, hai que ter en conta que todos os poemas teñen dous xéneros de progresión, unha máis extrovertida ou masculina, e a outra introvertida ou feminina:

La seguida y el rondel en sus extremos son el romance y la cantiga, como la marcha y el baile. Un rondel es un motivo con sus vueltas; el motivo tiene su síntesis y su adición propias, como un pequeño poema independiente, y las vueltas pueden ser sintéticas: -contra, con, deso aditivas: so, re, sin-, y también aunque más raramente, imaginarias: in, ante, entre y tras. Como vemos el motivo trabaja para sí, y las vueltas lo hacen en relación con él, y así decimos, por ejemplo, 'ante con motivo socontra vuelto', o 'reconvuelto', o 'antesincontravuelto', etc. (Azar 2013: 278)

Velaquí un exemplo de rondel composto dun motivo cunha soa volta, que habería que difinir: contra/con motivo reso volto:

Tal vai o meu amigo

con amor que ll'eu dei $/ \pm$ /

come cervo ferido

de monteiro de El Rei. /v>/

Tal vai o meu amigo, madre, con meu amor come cervo ferido de monteiro maior [...]"

(Pero Meogo, en Álvarez Blázquez 1952: 172; Nunes 1973: 373, 2)

Botándolle una ollada xeral ao poema rosaliano, observamos que ten catro estrofas, que comezan así cada unha delas:

1. Cando penso...

2. Cando maxino...

3. Si cantan es...

4. En todo estás... 
Nótase certa reiteración especialmente nas dúas primeiras estrofas, polo que se pode dicir que se trata de adición repetitiva ou restante; e, ademais, sabemos que o segundo verso "negra sombra que me asombras" é case igual que o último: "sombra que sempre me asombras". Por outra parte, observamos que o poema está tamén nun progreso que contradí a reiteración: de 'cando penso' pásase a 'cando maxino' e de 'si canto' a 'en todo estás'. Polo tanto, hai unha xuntanza das dúas adicións, re e $s o$, porque ao mesmo tempo que é repetición é progreso.

Así pois, imos comezar a análise partindo da hipótese de que "Negra sombra" ten o movemento feminino de rondel. Ao se tratar deste xénero, temos que prestar toda a nosa atención á primeira estrofa, que é a célula que, reiterándose dunha ou doutra maneira, fai o poema.

O celme do poema está no segundo verso, no sentido que lle deamos a 'asombras', pois pode verse, con respecto á negra sombra, como unha lápida tapa unha cova, e entón xa toda a estrofa e o poema enteiro non será mais que un laio por esta morte.

Cando penso que te fuches, negra sombra //+// que me asombras, /v/ ó pe dos meus cabezales tornas $/ *$ / facéndome mofa

Pero tamén podemos ver esta primeira estrofa como un progreso da fada invasora, pois o significado más propio de 'asombrar' non é o de 'ensombrecer' senón 'admirar'. Entón é cando se ve que o poema vai para arriba e non para abaixo, tal como expresa esa música sentimental que lle puxeron. Polo tanto, pódese representar tamén en adición soestante:

Cando penso que te fuches, negra sombra //>//que me asombras, / / ó pe dos meus cabezales tornas $/ * /$ facéndome mofa.

Pero esta ambigüedade, que é riqueza de forma e de fondo, non se vai comprender e o motivo vaise ver só como un contraste parado dominado pola morte, cando é tamén un crecemento valéndose dela. Agora imos ver se esta célula primeira medra aínda máis ou decae. A segunda estrofa ou primeira volta é:
Cando maxino que es ida, $/+>/$ no mesmo / $/$ /sol te me amostras, $/ \mathrm{v} /$ i eres $/ \equiv /$ a estrela que brila, $/ \mathrm{v} /$ i eres $/ \equiv /$ o vento que zoa.

Ao final do primeiro verso hai tamén un contraste, que reitera o do motivo; pero tamén se repite e acrecenta o sentimento de totalidade ata invadilo todo; polo tanto, a morte é derrotada pola vida.

Pasamos á terceira estrofa ou segunda volta. $\mathrm{Na}$ anterior a poeta atopaba a súa deusa no máis amplo para indicar a súa grandeza; aquí tamén no miúdo:

Si cantan /E// es ti que cantas;

si choran / $\equiv /$ es ti que choras;

i es/=//o marmurio do río,

i es $/ \equiv /$ a noite, $\mathrm{i}$ es $/ \equiv /$ a aurora.

A continuación, dáse o paso á filosofía. Partimos esta cuarta estrofa e terceira volta en dúas metades:

En todo estás e ti es todo

pra min i en min mesma moras,

A negra sombra está en todo, como vimos, e agora engádese que "é todo", e isto non é unha afirmación do sentimento poético, senón unha aseveración filosófica, de tres grados de alcance:
en todo estás
es todo para min
en min mesma moras

.É o 3) o que explica o 1) e o 2). A sombra está en todo e é todo para Rosalía, porque é ela mesma quen a fai, e polo tanto quen fai o mundo enteiro, aínda que a poeta non mande nela. E finalmente, da filosofía á relixión, pois agora trátase dunha fe:

nin me abandonarás nunca,

sombra / \pm / que sempre me asombras.

Este "asombras" é moi diferente do primeiro, pois aquel tiña sobre si o ensombrecemento da sombra, e este trae no seu seo todo o gañado ao longo do poema; aquel apenas se erguía e este voa. Trátase doutra mixtión no estilo de Juan de la Cruz.

Para que as árbores non empezan a contemplación do bosque, aquí temos o poema limpo: 
Cando penso que te fuches, negra sombra que me asombras, ó pé dos meus cabezales tornas facéndome mofa.

Cando maxino que es ida no mesmo sol te me amostras, $i$ eres a estrela que brila, $i$ eres o vento que zoa.

Si cantan, es ti que cantas, si choran, es ti que choras, $i$ es o marmurio do río, $i$ es a noite, $i$ es a aurora.

En todo estás e ti es todo pra min ien min mesma moras, nin me abandonarás nunca, sombra que sempre me asombras. (De Castro 1993a:170)

A continuación, faremos unha rápida segunda revisión matizando un pouco máis a análise. A primeira estrofa comeza pola parte ominosa desta meiga que, cando a poeta pensaba que non estaba, é cando aparece burlándose. Pero trátase ao mesmo tempo dunha pelexa e do comezo dun engrandecemento, como se mostra no que segue.

$\mathrm{Na}$ segunda estrofa reitérase e acrecéntase o contraste e a invasión: cando a poeta pensaba que xa se fora é precisamente cando a sombra adquire unha maior presenza. A natureza e o mundo enteiro tínguense da sombra. $\mathrm{Na}$ terceira estrofa, tanto se cantan coma se choran, tanto se é noite coma se é aurora, a poeta non vive máis que no sentimento da presenza da sombra.

$\mathrm{Na}$ primeira metade da cuarta estrofa a sombra só ten existencia respecto da poeta; polo tanto, non se trata dunha dualidade separada como pensabamos no comezo, senón dunha bilateralidade persoal: na poeta hai un algo que a fai dual. Ensombrécelle a vida e todo se lle fai máis triste; o páramo que hai na súa alma convértelle todo en morte. Non se trata de algo que se lle opoña fóra quedando ela pasiva; é a propia poeta a activa no seu vivir ensombrecido. Ata aquí non hai dúbida de que se trata dunha dación (a poeta) e dunha recepción (a negra sombra): "en todo estás e ti es todo para min"; pero o que segue contradíceo: "i en min mesma moras": o que estaba fóra na realidade está dentro, porque é a propia poeta quen se fai a si mesma estraña.

A segunda metade poderiamos considerala xa o sosego, como unha recapitulación e un acabamento, unha resignación do anterior considerado como laio; pero é todo o contrario, pois o poema convértese agora en fe, entre negativa e esperanzada: o desentrañamento, que é o seu mal que non ten cura, é tamén a súa única salvación.

- Definición:

- Fondo: invasión animista (trasfondo: desarraigamento creador)

- Forma: in ante tras descontra/sodescontra motivo re $4^{\circ}$ so contra/con volto.

- Ligazón: $1^{\mathrm{a}}$ propiciación; $4^{\mathrm{a}}$ tránsito.

O fondo e o trasfondo xa están explicados abondo. Respecto da forma, o motivo ou primeira estrofa ten o formante in porque a poeta válese máis da suxestión que da representación. Ten o formante ante porque "negra sombra" é unha metáfora do seu sentimento profundo. E ten o fomante tras porque no poema se produce unha transformación da agonista. Ademais disto, o motivo é ao mesmo tempo un contraste e unha burla (descontra), e un progreso contratrastando e burlando (sodescontra). E xa está todo dito respecto da célula inicial.

Logo veñen as estrofas restantes ou voltas, onde hai o formante re catro veces porque o poema consiste en catro estrofas reiterativas que son, ao mesmo tempo, crecemento ( $\mathrm{so}$ ) en contra e a favor: contralcon, polo tanto: re $4^{\circ}$ so contra/con. A ligazón 1P (propiciación) e 4T (tránsito) quere dicir que o poema non acada toda a súa grandeza ata a cuarta estrofa; non hai sosego. Trátase dunha verdeira definición, pois un poema (e unha sinfonía, e unha escultura) é a integración dun (tras)fondo cunhas determinadas formas, e iso é o que se intenta dilucidar aquí.

\section{CONCLUSIÓN}

No Propósito do comezo afirmábase que o trasfondo dun poema vital é o desentrañamento, que se xenera na vivencia primixenia 
do infante coa nai. A teoría é que tanto a arte como a vivencia espiritual teñen aí a súa orixe, e que este é o caso do poema "Negra sombra". Non ten que ser un sentimento exclusivo da nosa poeta, por iso fomos comparando esta obra con outra semellante dun poeta do que ela estivo sempre moi preto: Edgar Allan Poe, e tamén fomos vendo as concomitancias da negra sombra coa noite escura de Juan de la Cruz, ambas as dúas da mesma orixe.

Igual que o 'fondo', que se confundiu sempre co contido, tamén o concepto de 'forma poética' é novo na Teoría literaria; ningunha escola sabe dela (cf. Azar 2013: 40, 318, 385). Coa análise deste poema de Rosalía preténdese demostrar a funcionalidade de ambos os dous termos. Respecto da forma, antes de abordar a análise cumpría falar, tamén por primeira vez, dos dous xéneros poéticos, o rondel e a seguida. Partindo da hipótese de que "Negra sombra" pertence ao primeiro, puxémonos desde el a describir formalmente o poema, para chegar finalmente á definición, que consiste na representación, o máis aséptica posible, desta integración. Pero como un poema non é unha representación senón un sentimento vivido desde a intuición (Azar 207: 73), a representación non o acada a el mesmo, pois ¿que terá que ver esa recua de preposicións co sentiento de Rosalía? Unha cousa é o poema mesmo e outra o intento da súa representación, que pretende saber como está feito; e ese foi o noso labor.

\section{REFERENCIAS BIBLIOGRÁFICAS}

Álvarez BlázQuez, Xosé María (1952): Escolma de poesía galega. Vigo: Galaxia.

Azar, Xosé (2004): Vida masculino/femenina (edición electrónica: http://www.xoseazar.es/vida. pdf).

(2007): Poética de fondo (edición electrónica: http://www.xoseazar.es/poetica.pdf).

(2010): Rosalía erótica y existencial. Madrid: Editorial Manuscritos. pdf).

(2013): Poética formal (edición electrónica: http://www.xoseazar.es/poetica formal.

De CASTro, Rosalía (1993a): Follas novas (eds. H. Monteagudo e D. Vilavedra). Galaxia: Vigo. (1993b): Obras completas (ed. M. Mayoral). Madrid: Turner.

(1995): Cantares gallegos (ed. M. X. Lama). Galaxia: Vigo.

De la Cruz, Juan (19935): Obras completas (ed. J. Vicente e Ruiz). Madrid: Espiritualidad.

Murguía, Manuel (1975): Los precursores. A Coruña: La voz de Galicia.

Nunes, José Joaquim (1973): Cantigas d'amigo. Lisboa: Centro do libro brasileiro.

Poe, Edgar Allan (2000): Poesía completa (eds. M. Cóndor e G. Flaquera). Madrid: Hyperión. 